\title{
Granular Matter Transport in Vertical Pipes: The Influence of Pipe Outlet Conditions on Gravity-driven Granular Flow
}

\author{
Miha Jaklič, ${ }^{1}$ Klemen Kočevar, ${ }^{1}$ Stanko Srčič ${ }^{2}$ and Rok Dreu ${ }^{2, *}$ \\ ${ }^{1}$ Lek Pharmaceuticals, Verovškova 57, Ljubljana, Slovenia \\ ${ }^{2}$ Faculty of Pharmacy, University of Ljubljana, Aškerčeva 7, Ljubljana, Slovenia \\ * Corresponding author: E-mail: rok.dreu@ffa.uni-lj.si; \\ Tel.: +38614769622
}

Received: 07-09-2015

\begin{abstract}
Gravity transport of granular materials in vertical pipes is one of the most fundamental steps in bulk powder handling and processing. Presented study investigates powder flow characteristics in vertical pipes with open and closed outlets and condition of free powder fall. Powder flow of pharmaceutical grade powders was observed in transparent, vertical pipe model. Description of flow structures was performed. Powder volume flow rate, acceleration, and dilatation were quantified and correlated with powder properties. The results show that in pipes with a closed outlet the escaping air slows down the powder flow, resulting in a much slower flow than in pipes with an open outlet. A dense granular flow was detected in an open outlet condition, whereas in a closed outlet condition two concurrent flow regimes were observed: a slow moving, dense powder bed, and a fast dilute powder flow. Differences in flow regimes may promote segregation, with important implications to industrial processes.
\end{abstract}

Keywords: Vertical pipe; powder flow; granular matter; outlet conditions

\section{Introduction}

The gravity-driven flow of granular matter in vertical and inclined pipes is widely used for granular material transport between containers, production phases or it is integrated in a complex industrial processes such as circulating fluid bed reactors. ${ }^{1}$

Discharge from hoppers into vertical pipes was extensively studied experimentally. ${ }^{2}$ Pullen $^{3}$ investigated the effects of vertical pipes with free discharge (standpipes) attached directly to hoppers onto granular matter flow rates: he confirmed and quantified the effect of increased mass flow rates in this configuration, as opposed to no pipe at the hopper outlet. $\mathrm{Gu}^{4}$ similarly studied steady flows in a mass flow hopper alone and in combination with different length of vertical pipes connected to their outlet. Detailed measurements for powders (alumina, PVC powder, sand, and sugar) with a broad particle size distribution was performed in order to evaluate the effects of smaller particle size (median particle size range was from $80 \mu \mathrm{m}$ to $800 \mu \mathrm{m}$ ) on the pressure gradient at the pipe outlet, and consequently on mass flow rates in steady state of powder discharge. Furthermore, observations ${ }^{5-8}$ of granular flow released into vertical pipes with an air-tightly closed outlet (e.g. in pharmaceutical manufacturing) reveal air counter flow and an abrupt exit of air that causes extensive disturbances in the powder bed in the container and is a source of unwanted phenomena such as segregation.

Another area of research of granular material flow involves narrow vertical tubes (a tube-to-particle diameter ratio of $\sim 10$ ), where intermittent flow of particles is studied. ${ }^{9-11}$ Horikawa ${ }^{11}$ specifically reported a formation of density waves due to the back-flow of air rising through falling powder. Despite the non-applicability of the narrow tubes in industrial applications, the self-organization of particles into clusters with a distinct frequency distribution represents an important finding. Formation of density waves during a gravity granular flow in a vertical pipe occurs also only due to inelastic collisions in an airless environment, as was identified via a molecular dynamics simulation approach. ${ }^{12}$ 
There are numerous methods for measuring granular matter flow in process, which include mass flow measurements, mechanical and pressure sensors, optical photography, X-ray photography, X-ray and -ray tomography, and capacitance tomography. ${ }^{13,14}$ Optical methods are the obvious choice because of their simplicity and availability of the equipment. In general, two approaches are described: Particle image velocimetry (PIV), where bulk powder movement is evaluated and Particle tracking velocimetry (PTV), where individual particles are tracked. ${ }^{13}$

Besides experimental evaluation of granular flow in vertical pipes also theoretical models were developed: a one-dimensional mathematical model of steady state granular flow through a vertical pipe was described. ${ }^{15-17}$ It takes into account a granular flow due to gravity, drag force exerted to the granular phase by escaping gas, and interaction with the wall (in the dense flow regime). Theoretical models assume a steady and homogeneous flow of air, as well as that of the granular phase. However, an equations setup enables the handling of dense, as well as diluted granular flows. Furthermore, the presented equations setup can describe a multiplicity of flow regimes, where a moving bed flow and dilute flow co-exist depending on the flow conditions. ${ }^{17}$ A model describing gravity driven flow of small particles, where reduced flow rates were experimentally observed, was proposed. ${ }^{4} \mathrm{~A}$ practical, semi-theoretical approach was used for interpretation of coal flow from hopper: measured mass flow profiles were evaluated by set of equations describing the basic forces present in powder flow: gravity, buoyancy, drag force, inter-particle forces. $^{18}$

A granular two-phase flow exists in numerous states, which depend on its dilution with gas, however its naming is process-dependent: in gravity discharge vertical pipes, two states are usually described: a moving bed flow - plug flow and a suspension - dilute flow. ${ }^{19}$

Already presented studies on granular material flow (experimental, as well as theoretical) deal with well-developed, steady state flows. ${ }^{2-5,9-11,15-18}$ However, there is a lack of studies dealing with transient phenomena, such as flow initiation and halt. Thus, the motivation behind our study is to investigate the interaction between the granular flow and the air back-flow in a vertical pipe with an airtightly closed outlet (CO) and additionally to investigate the same powder materials also for granular flow characteristics in condition of open pipe outlet (OO), which is most often encountered condition in literature. For comparison purposes and to evaluate the influence of the pipe wall on gravity driven granular flow characteristics, a set of experiments was devised with the vertical pipe removed from the testing apparatus (WP - condition without the pipe). Our working hypothesis is that the vertical pipe outlet condition influences the powder flow pattern and transient phenomena, its acceleration, and the powder flow rate. Further on, a link between powder flow rates and bulk powder properties has been assessed.

\section{Materials and Methods}

\section{1. Materials}

The selected materials are pharmaceutical grade excipients with moderate flow properties, which can be used in the direct compression tableting process. The following commercial grade materials were tested: Emcompress AN (dicalcium phosphate anhydrous; DCPA) obtained from JRS Pharma (Mnf. Chicago Heights, IL, USA, B.N. 124741), Avicel PH 102 and Avicel PH 200 obtained from FMC BioPolymer (Cork, Ireland, B.N. 71250C and M1247C, respectively; MCC102, MCC200), SuperTab 14SD (spray-dried lactose; SDL) obtained from DMVFonterra Excipients GmbH (Nörten-Hardenberg, Germany, B.N. 10671590).

Powder bulk properties are presented in Table 1. Powder mass flow rate was determined by funnel method. ${ }^{20}$ Powder volume flow rate was then calculated from mass flow rate and powder bulk density. Angle of repose was measured on a Pharma Test PTG-2 instrument: 100

Table 1. Powder properties: bulk, tapped, ${ }^{8}$ and true densities, ${ }^{21}$ particle-size distribution $\mathrm{D}(0.1), \mathrm{D}(0.5) \mathrm{D}(0.9),{ }^{8}$ funnel measured mass and volume flow rates and angle of repose for tested materials, which include dicalcium phosphate anhydrous (DCPA), microcrystalline cellulose PH102 and PH200 (MCC102 and MCC200), and spray-dried lactose (SDL).

\begin{tabular}{|c|c|c|c|c|c|c|c|c|c|}
\hline $\begin{array}{l}\text { Material name } \\
\text { Abbreviation }\end{array}$ & $\begin{array}{c}\text { Bulk } \\
\text { density } \\
(\mathrm{g} / \mathrm{ml})\end{array}$ & $\begin{array}{c}\text { Tapped } \\
\text { density } \\
(\mathrm{g} / \mathrm{ml})\end{array}$ & $\begin{array}{l}\text { True } \\
\text { density } \\
(\mathrm{g} / \mathrm{ml})^{*}\end{array}$ & $\begin{array}{c}\mathrm{D}(\mathbf{0 . 1}) \\
(\boldsymbol{\mu m})\end{array}$ & $\begin{array}{c}\mathrm{D}(\mathbf{0 . 5}) \\
(\mu \mathrm{m})\end{array}$ & $\begin{array}{c}\mathrm{D}(\mathbf{0 . 9}) \\
(\mu \mathrm{m})\end{array}$ & $\begin{array}{c}\text { Mass } \\
\text { flow } \\
\text { rate }(\mathrm{g} / \mathrm{s})\end{array}$ & $\begin{array}{l}\text { Volume } \\
\text { flow } \\
\text { rate }(\mathrm{ml} / \mathrm{s})\end{array}$ & $\begin{array}{c}\text { Angle } \\
\text { of repose } \\
(\text { deg })\end{array}$ \\
\hline $\begin{array}{l}\text { Dicalcium phosphate anhydrous } \\
\text { DCPA } \\
\text { Microcrystalline cellulose (PH 102) }\end{array}$ & 0.688 & 0.811 & 2.89 & 14.68 & 131.75 & 251.25 & 4.63 & 6.73 & 30.6 \\
\hline $\begin{array}{l}\text { MCC102 } \\
\text { Microcrystalline cellulose (PH 200) }\end{array}$ & 0.347 & 0.470 & 1.59 & 34.83 & 103.67 & 218.00 & 1.20 & 3.46 & 33.7 \\
\hline $\begin{array}{l}\text { MCC200 } \\
\text { Lactose monohydrate (spray-dried) }\end{array}$ & 0.350 & 0.426 & 1.59 & 83.70 & 211.00 & 378.25 & 2.56 & 7.31 & 29.4 \\
\hline SDL & 0.610 & 0.711 & 1.545 & 37.70 & 107.50 & 213.75 & 2.56 & 4.20 & 28.2 \\
\hline
\end{tabular}

*True density values. ${ }^{21}$ 
$\mathrm{ml}$ of powder was left to flow through a $10 \mathrm{~mm}$ orifice while stirring onto a round horizontal base.

\section{2. Laboratory-Scale Model of a Vertical Pipe}

The experimental apparatus was a transparent, laboratory-sized model of a vertical pipe, with a $70 \mathrm{~mm}$ inner diameter. The setup consisted of an upper glass pipe - the powder container ( $800 \mathrm{~mm}$ high, top open to air), a knife valve (stainless steel, triggering mechanism for instant release, airtight design), a bottom glass pipe with a 1,200 $\mathrm{mm}$ drop, and an airtight valve at the bottom were used for the closed pipe outlet condition (Figure 1, left). For a detailed description, sketches and photographs of the testing apparatus, please refer to Jaklič et al. ${ }^{8}$

The open pipe outlet condition was accomplished by removal of the bottom airtight valve: the pipe outlet was completely open (Figure 1, middle). Below the pipe outlet a polyethylene bag was placed to collect powder materials, however, care was taken that airflow from the pipe outlet was not obstructed.

The condition without the pipe (i.e. powder release into the air) required complete removal of the vertical pipe (1200 mm segment), leaving only the powder container section $(800 \mathrm{~mm})$ and a knife valve, which were used to release the tested powders (Figure 1, right). In order to avoid excessive dusting and the accompanying hazards, a powder-receiving element was introduced at the bottom of the apparatus (please see the bottom sequence in Figure 2).

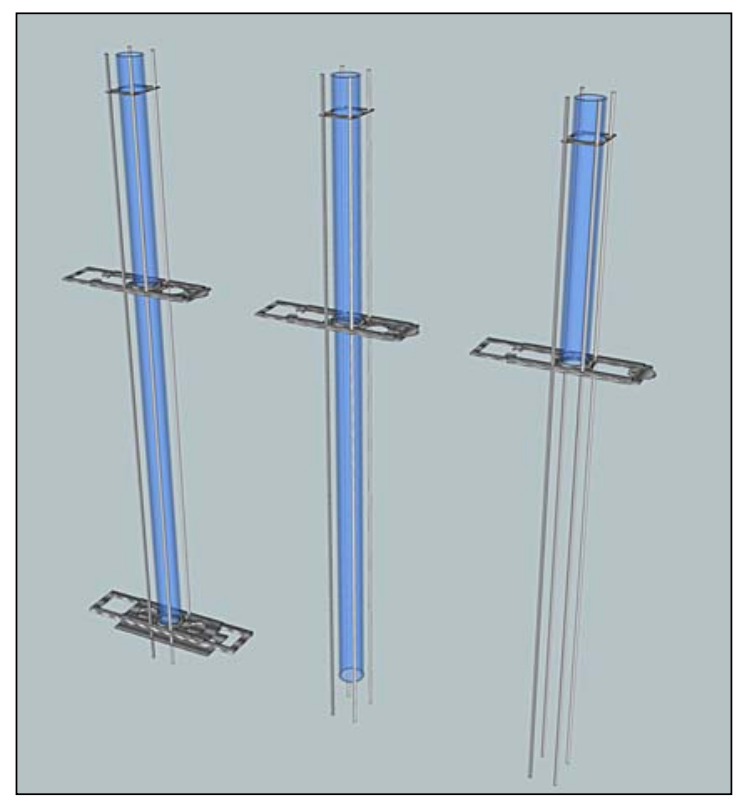

Figure 1. Sketches of the three setups used for powder flow experiments: closed outlet vertical pipe (left), open outlet (middle) and setup without the pipe (right), where the vertical pipe $(1200 \mathrm{~mm}$ drop region) is omitted.

\section{3. Vertical Pipe Powder Flow Experiments}

The knife valve was set in the closed position; the powder was poured into the container part of the apparatus to the pre-specified bed height of about $50 \mathrm{~cm}$ (corresponding to volume $\sim 1.9 \mathrm{~L}$ ). The material was then discharged from the powder container by releasing the knife valve. The material was left to drop with no additional mechanical intervention.

For each material three repetitions for a closed and open pipe outlet were performed. Two repetitions were performed in experiments, where the powder was released into the open space (condition without the pipe).

\section{3. 1. Powder Flow Visualisation}

Each experiment was recorded with two cameras: a Sony HDR-XR550V (HD, $25 \mathrm{fps,} \mathrm{exposition} \mathrm{time:} \mathrm{1/1250}$ s) was used for recording the whole length of testing apparatus (vertically aligned view field), and a Canon 5d MKIII (HD, 30 fps exposition time: 1/1250 s) with Canon 70200 L f/2.8 IS USM II lens (view field was vertically aligned and aimed to area below knife valve) was used for a close-up recording. Back-illumination of the transparent vertical chute resulted in depiction of powders as grey or black shades on a white background. A lateral image of the vertical pipe was produced by placing a mirror at an angle of $45^{\circ}$ next to the testing apparatus. LED lighting was set up for even back illumination of both frontal and lateral views of powder flow within the transparent vertical pipe.

\subsection{Image Extraction and Flow Feature Analysis}

The video acquired was further processed: FFmpeg video manipulation software (Fabrice Bellard, version 2015-01-02 git-75cc57f) was used to split each video file into a sequence of individual frames. Image $1.48 \mathrm{~s}$ imageanalysis software (Wayne Rasband, National Institute of Health, Bethesda, MD, USA; Fiji distribution) was then used to process the image sequences and perform data extraction from the images.

For closed outlet condition a condensed presentation of flow data was accomplished: image sequences (of XY dimensions) were organized into XYZ stacks where the $\mathrm{Z}$ dimension corresponds to time (one pixel per frame i.e. $0.04 \mathrm{~s}$ ). From these 3D stacks of images, slices in the YZ direction were extracted (with the $\mathrm{X}$ position fixed in the middle of the $\mathrm{X}$ dimension). The obtained images are referred to as spatial-temporal (ST) diagrams of powder flow. ${ }^{9}$ The three main features of powder fall (powder plug upper and lower boundary, sediment height) were extracted from spatial-temporal diagrams by means of image analysis: an edge detection algorithm was used (FeatureJ-Edges) and XY values extracted and scaled to match length and time units. Sediment height, extracted from the 
spatial-temporal diagram, can also be regarded as a recording of the material's volumetric flow.

\section{4. Evaluation Methods}

Analysis of powder volume flow rates, acceleration and dilution factor, powder plug descent rate, height decrease rate and sediment increase rate were performed in triplicate, and the median value is reported.

In the case of powder volume flow rate evaluation, the median value is reported as a result; however, also ranges are reported in order to enable the variability assessment.

\section{4. 1. Evaluation of Powder Volume Flow Rates}

In case of closed outlet condition powder flow after $700 \mathrm{~mm}$ descend was evaluated from stacked spatial-temporal data by determining the first time point where released powder descended for $700 \mathrm{~mm}$ and the last time point where $99 \%$ of the powder volume accumulation was identified: this approach was used due to fine dispersion of particles and their slow settling during the powder flow in closed outlet condition. Exact powder bed volume was assessed by evaluating initial powder bed height in the container region.

For an open outlet condition and condition without pipe, volume flow rates have been determined from time series of flow images. Two types of volume flow were determined:

- The powder volume flow after $700 \mathrm{~mm}$ of descend (pipe flow rate) was determined by identifying the first time frame where powder descended $700 \mathrm{~mm}$ and the last time frame where the majority of powder bed passed the $700 \mathrm{~mm}$ mark; slowly settling, air-born powder was thus excluded.

- The powder volume flow during the discharge from the container (discharge flow rate) was determined by identifying the first time frame of powder release and the time frame at which powder was completely released from the container.

\section{4. 2. Powder Acceleration and Dilution Factor}

The powder front (all outlet conditions) and upper boundary positions of the powder plug (open outlet condition and condition without the pipe) were assessed from the frame sequence using image $J$ measurement tools and visual confirmation of the powder front and plug position. The results were scaled to match length and time units. Powder plug acceleration was determined as a double slope value of linear fit to the data of bed position vs. time squared. Powder front acceleration was determined in equivalent manner.

Dilution factor could be calculated only for closed outlet pipe condition. The dilution factor is defined as a ti- me averaged ratio of average dispersed flow density to powder bulk density. Dispersed flow density was calculated by subtracting the sum of sediment and plug length from the initial bed height, and then divided by the distance between the lower plug boundary and sedimentation front. Stacked spatial-temporal data were used to obtain time averaged value.

\section{4. 3. Powder Plug Descent Rate and Height Decrease Rate}

Parameters of powder plug descent rate, plug length decrease rate as well as sediment increase rate were calculated from respective slopes, identified from the stacked spatial-temporal data. Powder plug and sediment boundaries were identified by means of image analysis: an edge detection algorithm was used (FeatureJ-Edges). XY values were extracted and scaled to match length and time units. Upper plug edge was used for identification of plug descent rate. Its position was fitted to exponential decay function, using Minitab 16, Minitab Inc. Plug length decrease rate was obtained by subtracting positions of upper and lower boundaries of powder plug.

\section{4. 4. Evaluation of Powder Detachments in Pipe With Closed Outlet}

Powder flow in closed outlet is governed by series of detachments of powder chunks from powder plug, which is recorded on spatial-temporal profiles. Intensity profiles of spatial-temporal profiles were obtained (a line $70 \mathrm{~mm}$ below the valve knife was labelled and intensity profile extracted (imageJ: PlotProfile command)). A fast Fourier transformation (FFT) analysis was performed with OriginPro (ver. 8.0.63.998, OriginLab Corporation).

\section{4. 5. Correlating Powder Flow Characteristics to Powder Properties}

Powder volume flow rates were correlated with bulk powder properties (Table 1) by calculating the Pearson correlation coefficients of the linear regression models. The proportion of the total variation was assessed using the coefficient of determination $\left(\mathrm{R}^{2}\right)$. The calculations were made using IBM SPSS Statistics Version 22.

\section{Results and Discussion}

\section{1. Powder Flow Transient Phenomena}

Powder flow was observed on frame sequences, compiled from original footage: a representative case of microcrystalline cellulose (MCC102) for the three tested conditions is presented in Figure 2. A detailed description of granular flow of each individual pipe outlet is discussed in the following paragraphs, a close-up frontal and lateral 

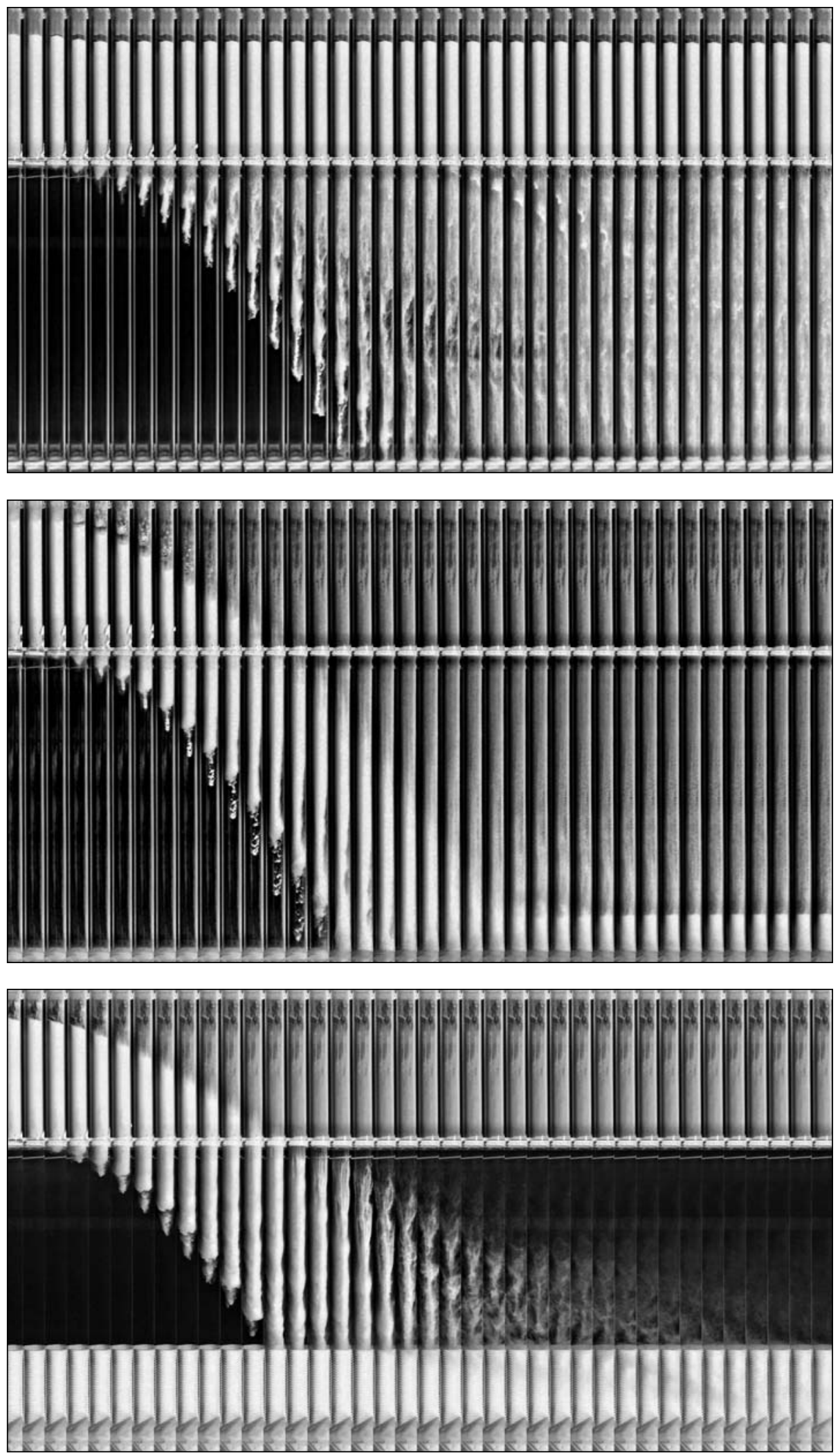

Figure 2. Sequences of 38 frames with a $0.04 \mathrm{~s}$ time interval from the three experiments with microcrystalline cellulose (MCC102): the closed pipe outlet condition (top sequence; please observe that only a small part of the powder is released from the container), the open pipe outlet condition (middle sequence; powder falls in the form of a dense powder flow), the condition without the pipe (bottom sequence; the pipe is removed and a bottom powder receiving element is introduced in this case; the dense powder flow is observed). Total depicted experiment time: $1.52 \mathrm{~s}$. The original images are inverted and contrast enhanced for illustration purposes. 
footage of flow structures for all tested materials are presented in Figure 4, Figure 5 and Figure 6.

\section{1. 1. Description of Powder Flow Patterns in a Pipe With Closed Outlet}

An examination of powder fall in a pipe with an airtightly closed outlet (Figure 2, top sequence) reveals a multitude of features involved in powder descent. A small (20-50 mm), however fast powder plug drop in the first 0.2 s (i.e. 5 frames) was observed. On the lower part of the powder plug, a detachment of material, its fall and dispersion in the air is observed; this is followed by further similar discrete detachments of powder from the lower part of powder plug. In the time frame presented (1.52 s), only a small fraction of the material is discharged from the powder container. In Figure 3 whole sequence of powder flow is shown $(12.32 \mathrm{~s}$, frames separated by $0.28 \mathrm{~s})$ : the powder plug in the container part is slowly descending, its height is gradually reduced and finally the powder plug ruptures. At the bottom of the pipe, sediment is formed and its height in conjunction with time frame position is a direct measure of the powder volume flow.

Upon the powder release the powder plug initial drop is counterbalanced (and stopped) by overpressure, which is formed below the powder plug. Despite the absence of actual pressure measurements, the presence of overpressure may be deduced from powder plug stoppage and its fluidization, which occurs upon its rupture (Figure 3). A dispersed state of the falling material can be clearly observed in Figure 4: the first segment of dispersed pow- der transforms into spike-like structures, which are very similar to Rayleigh-Taylor instability, usually observed when a fluid with larger density begins to flow into a fluid with a lower density. Atwood number can in case of granular flow be defined as ratio of a density difference of penetrating and penetrated phase and a sum of both densities and can be interpreted as a measure of overall flow pattern spikiness. ${ }^{22}$ For the initial fragment of the detached material, the value of the Atwood number is high (calculated value for MCC102 is 0.99), therefore flow structures with pronounced spikes of heavier granular matter and bubbles of escaping air are formed..$^{23,24}$

A lateral view of the falling structures (Figure 4) reveals that the material fall is strongly influenced by knife valve movement. The knife valve is released from the proximal side to the distal part of the pipe (i.e. in the direction away from the observer). The material which is released first (proximal part of the pipe) stays on the side of the pipe where it was released (the proximal part corresponds to right side on the picture (Figure 4 - L part), so most of the material observed in the first drop is actually present in the proximal part of the pipe. This structure is stable until the first part of the detached material reaches the bottom (not shown on photographs). The initial condition of the granular material movement is imposed by the knife valve. On the proximal side of the pipe, powders descend near the wall: it may be deduced that the displaced air travels upward along the distal part of the pipe. This organisation of flow is not maintained throughout the powder flow, since in the middle time section of the material flow a dispersed flow was occupying the whole pipe diameter

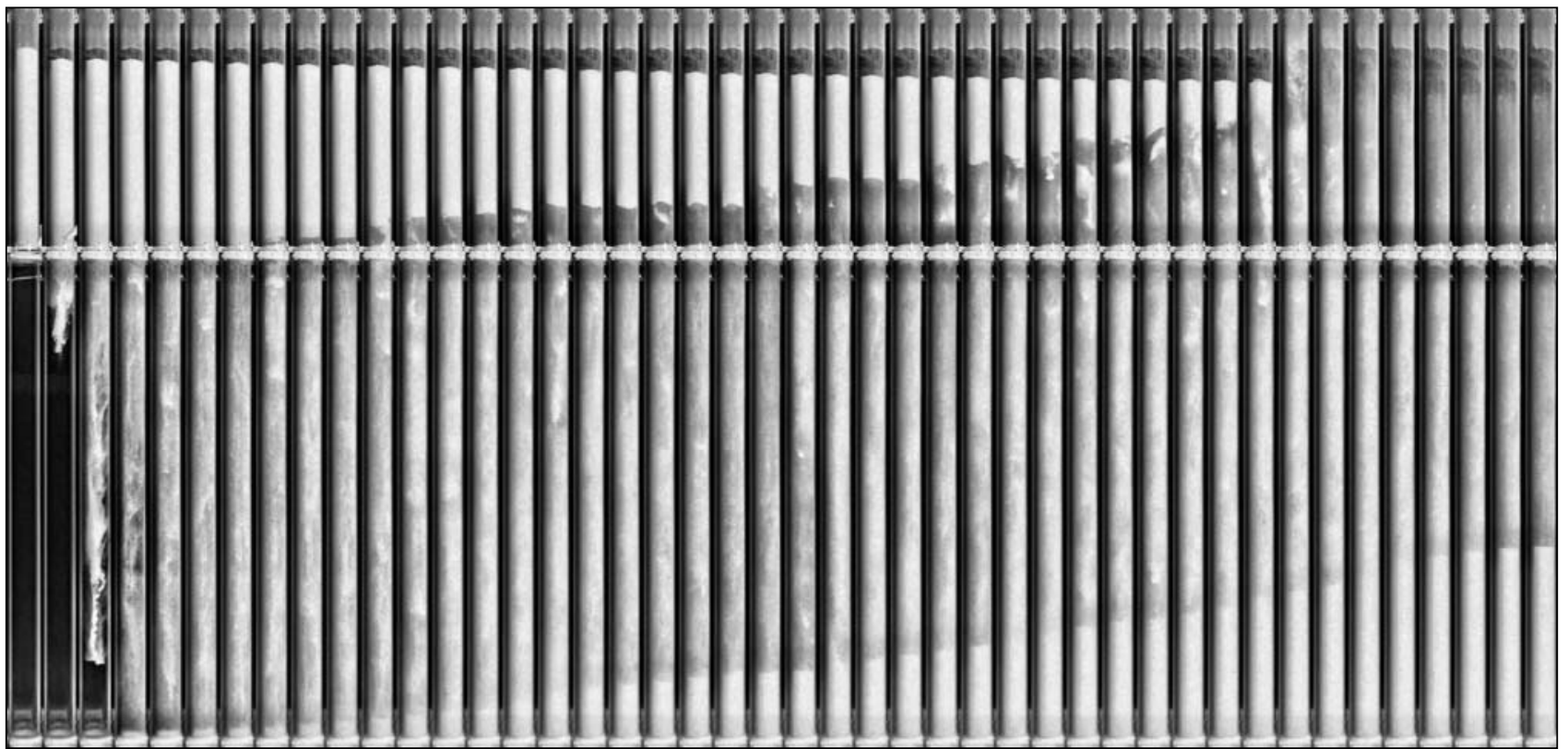

Figure 3. Sequence of 44 frames with $0.28 \mathrm{~s}$ time interval from the airtight closed pipe outlet experiment with microcrystalline cellulose (MCC102). The depicted experiment time: $12.32 \mathrm{~s}$. The four distinctions of powder fall are clearly observable: the upper plug descends and the discrete detachment of material, the dispersion of the detached material in air, and the accumulation of sedimented material at the bottom of the pipe. The original images are inverted and contrast enhanced for illustration purposes. 
(Figure 4, bottom row). There are no pronounced differences between the powder flow patterns of the tested materials.

Powder flow in a pipe with closed outlet is mainly in a steady state (Figure 3, Figure 6). Transient phenomena is limited to beginning of flow, when first packet of detached material falls to the bottom of the pipe, and to the end of the flow - after the powder plug rupture.

\section{1. 2. Description of Powder Flow Patterns in a Pipe With Open Outlet}

Flow pattern in simpler in the pipe with an open outlet. Powder flow is presented on a large scale in the middle sequence of Figure 2 and as a close-up depiction in the top part of Figure 5. The powder bed starts to move due to gravitational acceleration and falls as a continuous structure to the very bottom of the pipe. The powder flow is fast and the whole volume of powder $(1.9 \mathrm{~L})$ is released from container part more or less as a uniform body in less than a second $(0.8 \mathrm{~s})$. Close-up footage of
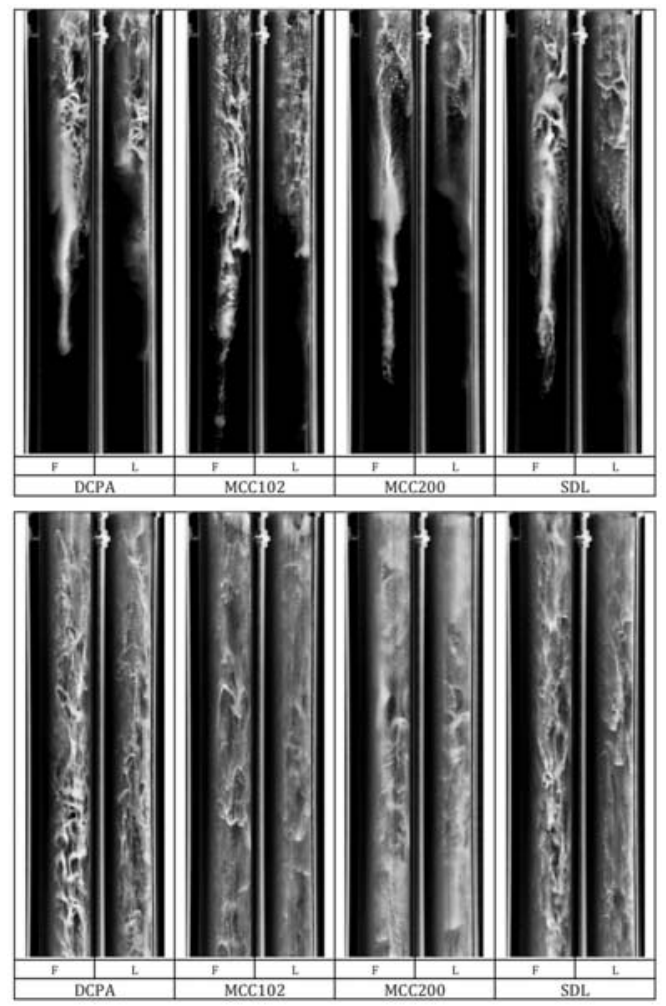

Figure 4. Close-up photographs of the powder fall for closed outlet condition (upper $1 / 3$ of the pipe). The top row consists of photographs of spike-like structures of the first packet of detached material, while the bottom row consists of photographs of dispersed flow (approximate medium sequence section for each material). The presented images include frontal $(\mathrm{F})$ and lateral $(\mathrm{L})$ views of tested materials: dicalcium phosphate anhydrous (DCPA), microcrystalline cellulose MCC102 and MCC200, and spray-dried lactose (SDL). The original images are inverted and the contrast enhanced for illustration purposes. the initial powder bed shows a very dense structure. However, some of the material is preceding and accelerating faster than the main powder plug front. This part of the material is released first during the powder discharge by the knife valve.

Falling powder bed is counterbalanced by air drag and by the particle friction with the pipe wall. The powder plug dilates, transforms into a spike-like structure and entraps some air. Near the bottom of the pipe this phenomena is observed as air bubbles between the plug and pipe wall, which travel concurrently with the powder plug. Furthermore, the upper part of the powder plug loses its sharp boundary, most probably due to air-driven dispersion of the upper layer of the powder plug.

Also, in this case the knife valve influences the powder flow: some of the material is released prior to the main plug, and also the bottom part of the plug is shaped according to the knife valve movement (observable on lateral images of Figure $5-\mathrm{L}$ ). The plug released into the pipe is slightly thinner than the initial powder bed width, and some air entrapment is observable at the very
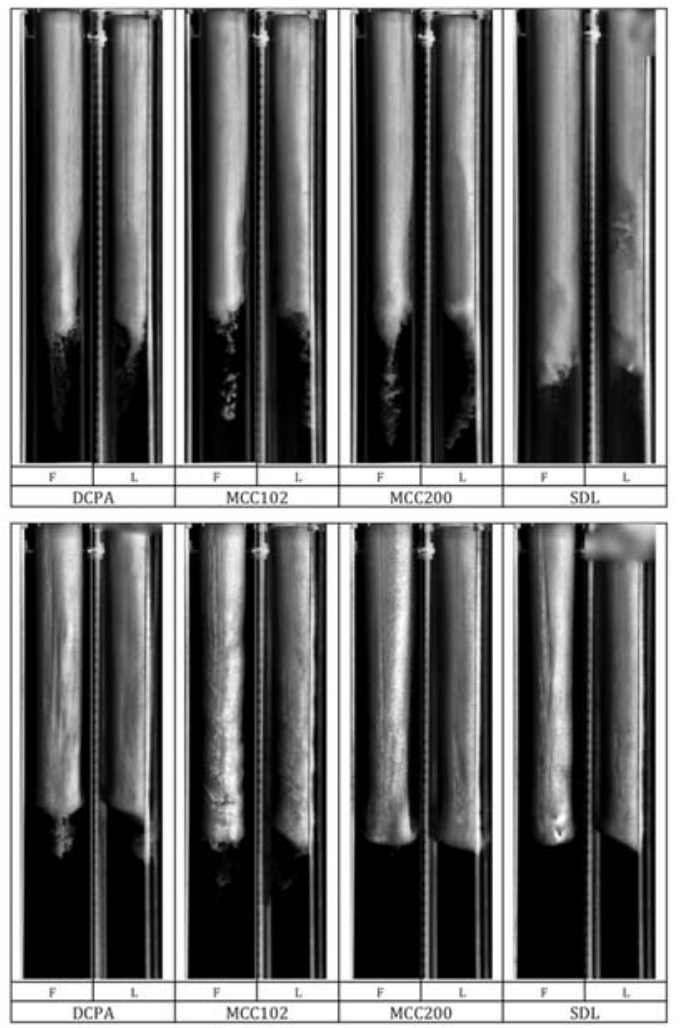

Figure 5. Close-up photographs of the powder fall (upper 1/3 of the pipe). The top row photographs show the powder plug in the vertical pipe with an open outlet, while the bottom row are photographs of the powder plug released into the air (condition without the pipe). The presented images include frontal $(\mathrm{F})$ and lateral $(\mathrm{L})$ views of the tested materials: dicalcium phosphate anhydrous (DCPA), microcrystalline cellulose MCC102 and MCC200, and spray-dried lactose (SDL). The original images are inverted and the contrast enhanced for illustration purposes. 
beginning of the powder fall. All tested materials behave similarly.

Observed flow in a pipe with an open outlet is a transient phenomenon; as is evident from time sequences (Figure 2) powder plug still accelerates even after 1200 mm fall.

\section{1. 3. Description of Powder Flow Patterns in Condition of Unconfined Flow}

In order to evaluate the influence of pipe walls on powder flow experiments without a vertical pipe were performed. Release of powder into the void, i.e. air (Figure 2, bottom sequence, Figure 5 - bottom row) shows a very clear picture of powder plug surface morphology during the fall: the microcrystalline cellulose (MCC102, material with lowest measured funnel flow) surface appears to segment during the fall. The surface of the microcrystalline cellulose (MCC200, material with largest particles) and DCPA appear to have particles sheared off at the edge of the powder front.

The powder bed accelerates very fast and falls as a whole towards the bottom. The mode of fall is very similar to that of a pipe with an open outlet and also in this case a transient flow is observed. Details of the powder fall (Figure 2) show that some of the material precedes the main powder plug front, however in this case main powder front catches up with the preceding part. The powder front is, in this case, influenced by surrounding standing air, which is observable by shearing of the material on the edges of the powder front. Again, elongation of the powder plug is observed (Figure 2, bottom sequence). The surface of the powder plug shows undulations - a structure strongly resembling Rayleigh instability. A possible explanation for this phenomenon is friction minimization at the powder-air interface: a cylinder-shaped powder bed is not an aerodynamically optimal structure and transformation into sphere (drop)-shaped fragments takes place. However, the drop height is too low for the transformation to complete. The upper boundary of the powder plug is easily detectable while still in the powder container, however after the passage of the knife valve it is transformed into a tail-like structure.

\section{2. Quantitative Analysis of Gravity Driven Powder Flows}

Transparent experimental setup enabled camera recording of powder flow structures. Extracted images were the basis for quantification of powder flows: volume flow rates and acceleration were assessed for all tested outlet conditions, whereas for the closed outlet condition the spatial-temporal diagrams enabled additional assessment of powder plug length and spatial position evaluation, material detachment frequency, powder dilution with air and sediment increase rate.

\section{2. 1. Dynamics of Powder Flow in Pipe with Closed Outlet Condition}

Spatial-temporal diagrams for closed outlet experiments provide a condensed view of materials flow over longer time periods. Each frame in Figure 3 is presented in a form of one vertical line in Figure 6.

\section{2. 1. 1. Powder Plug Detachment Rate}

On a typical spatial-temporal diagram (Figure 6), three distinct regions were observed: the powder plug (upper part) with its upper and lower limits, the intermediate region where the fall of detached powder chunks is recorded as stripes, and the lower region where material deposition is recorded.

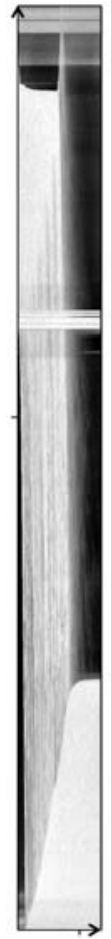

DCPA

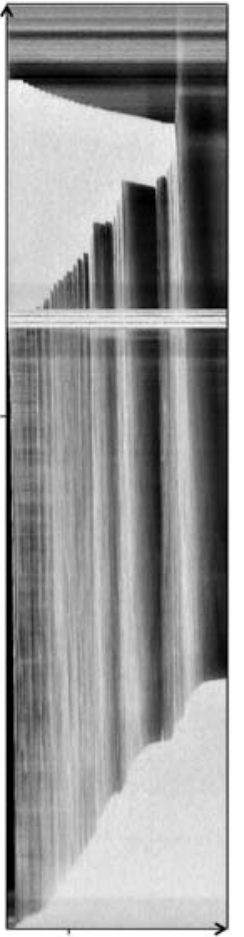

MCC102

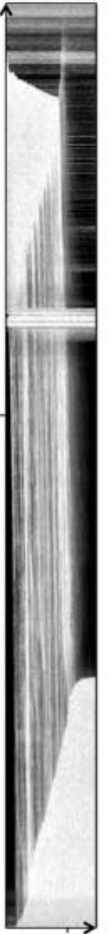

MCC200

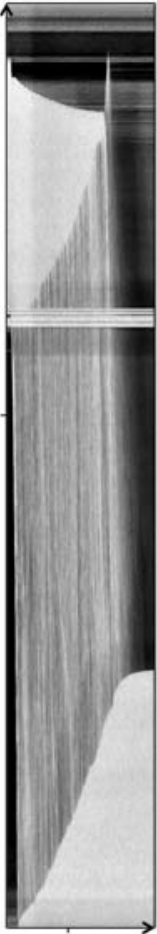

SDL
Figure 6. Spatial-temporal images of powder flow in pipes with a closed outlet for all tested materials: dicalcium phosphate anhydrous (DCPA), microcrystalline cellulose MCC102 and MCC200, and spray-dried lactose (SDL). Horizontal marks at the image bottom correspond to $5 \mathrm{~s}$, and the vertical left positioned lines correspond to $1000 \mathrm{~mm}$. The original images are inverted and the contrast enhanced for illustration purposes.

Materials with high volume flow have a high detachment rate and large partial volumes of detached material, which is observed in the dynamics of the lower boundary of the powder plug, and can also be observed in the sediment height rate increase. The detachment rate and size of the powder portions are the powder flow rate limiting factors for the powder flow in pipes with a closed outlet. The detachment event is a complex phenomenon, which depends on the inter-particle interactions and par- 
ticle-wall interactions. Inter-particle interactions will strongly depend on particle shape, size and size distribution, mechanical interlocking, particle packing, inter-particle forces. Particle-wall interaction will depend on pipe properties such as pipe diameter, wall roughness, wall friction. In our case a smooth, glass pipe with large diameter (compared to particle diameter) was used. Detachment events should correlate with the Mohr-Coulomb failure criterion, which is most often used to describe a rupture in granular beds, ${ }^{19}$ however detailed study of detachment events is beyond the scope of this report.

Careful inspection of the powder plug movement (the upper boundary is an effective indication of the powder plug position) is intriguing. After the knife valve release, an initial drop in powder plug was recorded, as explained earlier, followed by a slow, step-wise descent, which does not cease even if the material flow stops (i.e. no detachment of the material from the lower part of the powder plug occurs). A slow descent of the powder plug indicates that permeation of air through the powder plug is taking place, which can be regarded as a plug flow and is a way for powder to descend, even in the case of cohesive powders where no detachment occurs.

Dicalcium phosphate anhydrous (DCPA) has the highest volume flow rate, and the detachment rate from the bottom part of the powder plug is very high. Individual detachment events are barely observable (detachments are frequent and detached fragments are large). The uniform slope of the sedimentation part indicates a very constant volume flow. Microcrystalline cellulose (MCC102) shows the longest flow time: the detachment frequency is at first quite high, however, it seems that detached fragments are small. In the case of MCC102, there are two regions with stagnant flow where no detachment was recorded (Figure 6 ). Despite that, the powder plug slowly travels down the pipe with a constant descent rate of about $5 \mathrm{~mm} / \mathrm{s}$, corresponding to the local volume flow of about $20 \mathrm{ml} / \mathrm{s}$. The last part of the powder plug ruptures and is to a part fluidized by escaping air, which is evident from the spatial-temporal diagrams in the form of a spike in the upper part of the picture (this behaviour was observed for all materials). In the case of microcrystalline cellulose with larger particles (MCC200, Figure 6), a fast flow was observed, however also a very fast descent of the powder plug was detected: this is a consequence of more porous MCC200 powder bed with higher air permeability. The spray-dried lactose flow is very constant with seemingly evenly spaced detachments of powder. Fast Fourier Transform analysis (FFT) of time limited intensity profiles (Figure 7) extracted from spatial-temporal diagrams did not reveal any periodic behaviour. However, this is not completely deterministic with regard to periodicity of material detachment as there might simply not be enough detachment events for the characteristic frequency to emerge as result of FFT analysis.

Friction between powder plug and glass pipe walls seems to be low because of the very fast initial fall of the

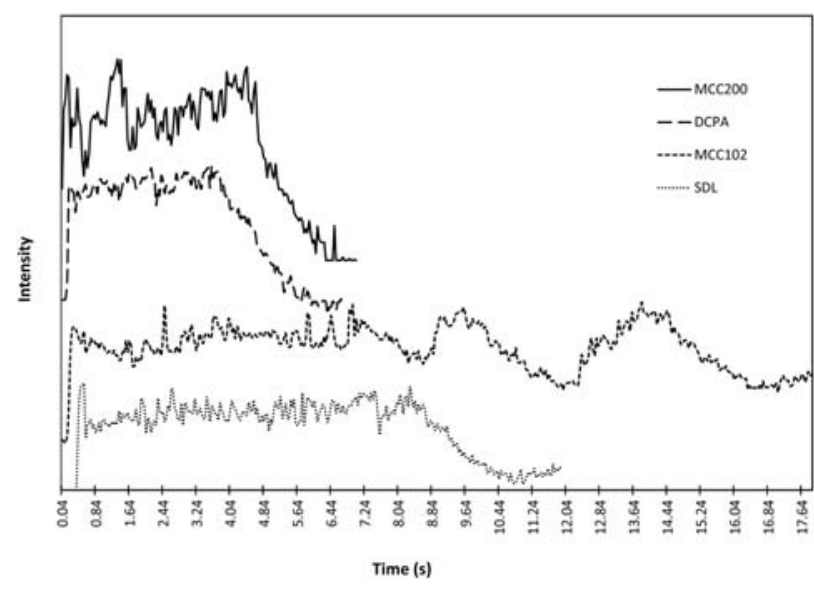

Figure 7. Intensity profiles of spatial-temporal images for all tested materials: dicalcium phosphate anhydrous (DCPA), microcrystalline cellulose MCC102 and MCC200, and spray-dried lactose (SDL). Each peak corresponds to one detachment event: intensity is presented on $\mathrm{Y}$ axis without units for purpose of improved illustration.

powder plug and very frequent, step-wise lowering of the powder plug during air permeation. The stepwise characteristics of the plug descent could be the consequence of the difference between static and dynamic friction coefficient values, which could be the reason for transitions from one force equilibrium to another, while air passes through the porous plug of particles.

\section{2. 1. 2. Plug Flow Phenomena}

Spatial-temporal diagrams for the closed outlet condition (Figure 6) enable a detailed evaluation of powder fall dynamics and calculation of fall parameters. Powder plugs can be characterized by two distinct parameters: powder plug position (characterised by powder plug top surface) and powder plug length (calculated as the difference between the powder plug top surface and bottom surface). The powder plug travels downward in a distinct pattern: the initial fast drop of the powder plug is followed by the plateau, which is in turn followed by a gradual descent, which resembles exponential decay - a fitting to the exponential decay function was performed. The results $(\boldsymbol{\lambda}$ - exponential decay constant) are presented in Table 2. The exponential decay of upper plug boundary position is fastest in case of DCPA, followed by MCC200, SDL and MCC102. With the exception of MCC102, which exhibits a stagnation of powder flow, the powder plug length linearly decreases over time for all tested materials - which is a good indication that the overall detachment rate from the powder plug is constant. The average slope of powder plug length reduction is the steepest for DCPA and MCC200, and the lowest for MCC102, which is in line with measured funnel flow data (Table 1) for these materials.

The mechanism behind the exponential decay of the powder plug in closed outlet conditions is not completely 
Table 2. Powder plug descent dynamics (upper part), powder plug length decrease rate, dilution factor and sediment increase rate for the closed pipe condition and all tested materials: dicalcium phosphate anhydrous (DCPA), microcrystalline cellulose MCC102 and MCC200, and spray-dried lactose (SDL).

\begin{tabular}{lcccc}
\hline $\begin{array}{l}\text { ST diagram } \\
\text { parameters }\end{array}$ & $\boldsymbol{\lambda}$ (exp. decay) & $\begin{array}{c}\text { Powder plug length } \\
\text { decrease rate }(\mathbf{m m} / \mathbf{s})\end{array}$ & $\begin{array}{c}\text { Dilution factor (dispersed flow } \\
\text { vs. powder bulk density) }\end{array}$ & $\begin{array}{c}\text { Sediment increase } \\
\text { rate }(\mathbf{m m} / \mathbf{s})\end{array}$ \\
\hline DCPA & 2.005 & -164.3 & 0.040 & 129.4 \\
MCC102 & 0.066 & -43.1 & 0.031 & 43.3 \\
MCC200 & 0.450 & -145.7 & 0.049 & 121.6 \\
SDL & 0.242 & -59.2 & 0.056 & 53.0 \\
\hline
\end{tabular}

obvious; however a possible explanation is the following: each detached part of the powder plug causes displaced air to push the powder plug upward (a local overpressure is formed). With powder bed decrease and a constant detachment rate, the influence of the detached material on the powder plug descend rate effectively increases, resulting in the reduced speed of the powder plug descent. Interestingly, in some cases the powder plug descends in a stepwise manner. The overpressure, which is present below the plug, is reduced due the permeation of air through the powder plug. Once the pressure is sufficiently reduced to overcome the force of static friction, the powder plug descends; in some cases the descent is followed by a slight increase in powder height, which is best explained by a damped oscillation movement. As outlined above, there is a complex interplay of different mechanisms, which are governing the powder plug descent in the pipe with a closed outlet.

\section{2. 1. 3. Dilute Powder Flow and Sedimentation Quantification}

In the closed outlet condition, powders detached from powder plug are fully dispersed in the air: to quan-

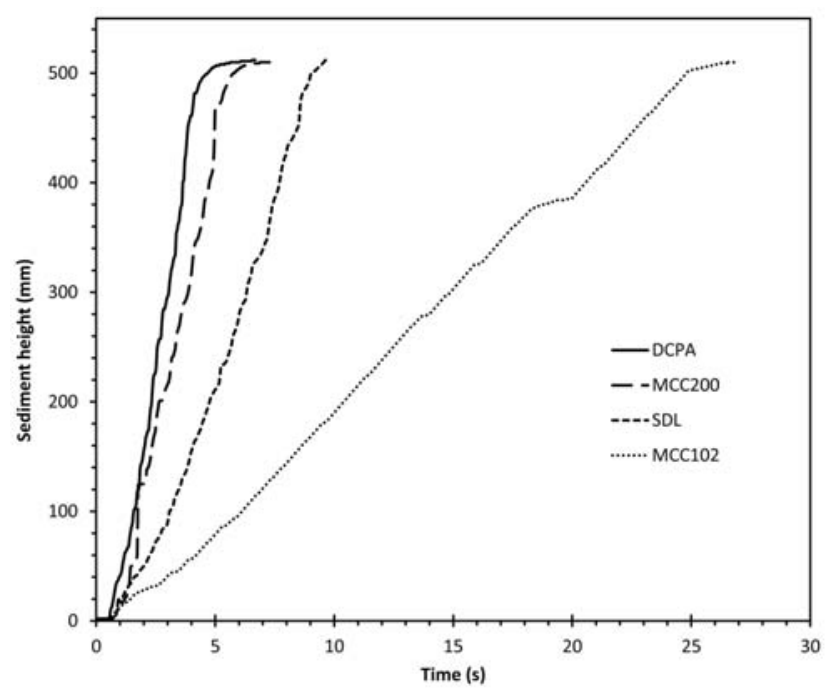

Figure 8. Sediment height increase over time in pipe with a closed outlet for all tested materials: dicalcium phosphate anhydrous (DCPA), microcrystalline ce llulose MCC102 and MCC200, and spray-dried lactose (SDL). tify density of dispersed powder suspension a new term "dilution factor" was introduced. Dilution factor was expressed as a time averaged ratio of dispersed flow density to powder bulk density. Dilution factor results are presented in Table 2. The dilution factor is the lowest for MCC102, which is in line with the observed dilute flow and occurs due to the low detachment rate. The volume fraction of solids can be calculated for non-porous DCPA particles - based on the dilution factor and bulk, and true density. ${ }^{21}$ The estimated solids volume fraction is $0.95 \%$, which indicates a very dilute granular flow.

Observation of the powder sediment height increase over time (Figure 8) shows that sedimentation rate is linear in initial and medium regions, followed by a gradual decrease, corresponding to the settling of air-borne powder. During the stoppage of powder flow, the sedimentation region asymptotically approaches the maximum value. If there are several powder flow stops (stagnant flow) this results in an alternation of linear and non-linear regions, following the final powder flow cessation (as is the case for MCC102, Figure 8).

A comparison of detachment (powder plug length decrease) and sedimentation slopes (Table 2) shows that the rate of powder plug length decrease is higher than the rate of sediment increase for powders with high funnel flow rates (Table 1), which indicates that more of the powder will be air-borne during powder fall, and hence the difference in slopes. For powders with low funnel flow rates, e.g. MCC102, both slopes were similar, since powders have had enough time for settlement between the detachment events. Complete dispersion of material and dilute flow in the case of the closed outlet condition as opposed to the open outlet condition can influence segregation, as previously reported by the authors. ${ }^{8}$

\section{2. 2. Acceleration of Granular Flow in Pipes With Different Outlet Conditions}

The acceleration of the powder plug front and the powder plug body (measured as acceleration of its upper boundary) are presented in Table 3 . In the open outlet condition and the condition without the pipe acceleration of the powder plug front is faster than that of its upper boundary. This is a consequence of the powder plug front wall - localized mixing with air, which improves the flowabi- 
Table 3. Acceleration of the powder plug front and body for closed and open outlet conditions, and the condition without the pipe for all tested materials: dicalcium phosphate anhydrous (DCPA), microcrystalline cellulose MCC102 and MCC200, and spray-dried lactose (SDL).

\begin{tabular}{|c|c|c|c|c|c|c|}
\hline & \multicolumn{6}{|c|}{ Acceleration $\left(\mathrm{m} / \mathrm{s}^{2}\right)$} \\
\hline & \multicolumn{2}{|c|}{ Closed outlet } & \multicolumn{2}{|c|}{ Open outlet } & \multicolumn{2}{|c|}{ Without the pipe } \\
\hline & Front & Body* & Front & Body & Front & Body \\
\hline DCPA & $\begin{array}{c}7.9 \\
(7.4-8.1)\end{array}$ & - & $\begin{array}{c}8.0 \\
(7.7-8.0)\end{array}$ & $\begin{array}{c}5.0 \\
(4.5-5.2)\end{array}$ & $\begin{array}{c}7.9 \\
(7.8-7.9)\end{array}$ & $\begin{array}{c}5.4 \\
(5.3-5.4)\end{array}$ \\
\hline MCC102 & $\begin{array}{c}6.6 \\
(5.6-6.8)\end{array}$ & - & $\begin{array}{c}8.2 \\
(7.5-8.5)\end{array}$ & $\begin{array}{c}3.9 \\
(3.2-5.0)\end{array}$ & $\begin{array}{c}7.5 \\
(7.4-7.5)\end{array}$ & $\begin{array}{c}4.5 \\
4.2-4.7)\end{array}$ \\
\hline MCC200 & $\begin{array}{c}7.2 \\
(6.2-8.4)\end{array}$ & - & $\begin{array}{c}9.9 \\
(9.6-9.9)\end{array}$ & $\begin{array}{c}6.5 \\
(5.1-6.5)\end{array}$ & $\begin{array}{c}8.1 \\
(7.3-8.9)\end{array}$ & $\begin{array}{c}4.2 \\
(2.2-6.1)\end{array}$ \\
\hline SDL & $\begin{array}{c}6.4 \\
(4.7-6.9)\end{array}$ & - & $\begin{array}{c}8.6 \\
(8.6-8.8)\end{array}$ & $\begin{array}{c}6.4 \\
(5.9-6.8)\end{array}$ & $\begin{array}{c}7.8 \\
(7.6-8.2)\end{array}$ & $\begin{array}{c}5.0 \\
(4.8-5.1)\end{array}$ \\
\hline
\end{tabular}

*In the closed outlet condition the powder plug body does not accelerate.

lity of the powder and reduces the friction with the pipe wall. Friction with the pipe/container wall is probably contributing to holding back the upper part of the powder bed. General ranking of powder front acceleration values is the following: acceleration is the slowest for the closed outlet, followed by the condition without the pipe and is fastest for open outlet condition. The observed trend is valid for all materials; however, for DCPA the acceleration values for all three conditions are similar. These results clearly demonstrate the influence of air on powder movement. In the closed outlet condition air backflow reduces the acceleration of the falling powder front. In the condition without the pipe, the powder bed accelerates through standing air. In the open outlet condition, the powder bed is being de-accelerated the least since the moving powder also moves the air within the pipe. The concurrent flow of entrapped air and the powder bed is also observable on footage of the open outlet. In addition, faster acceleration of the material, which precedes the main powder bed front, also indicates a concurrent air-powder flow. ${ }^{3}$ The powder front acceleration parameter did not resolve the differences between materials, however it clearly demonstrated the differences in different outlet conditions.

Powder plug body acceleration is about $25-50 \%$ lower than powder front acceleration. In contrast to powder front acceleration no clear influence of testing condition (open outlet or condition without the pipe) or material type on powder body acceleration was identified.

\section{2. 3. Pipe Volume Flow Rates in Different Outlet Conditions}

Powder flow measurements - as presented in Table 4 and Figure 9 - reveal that powder volume flow rate in closed outlet condition is by an order of magnitude lower than in an open outlet or a condition without the pipe: the effect was expected, however the extent of observed differences is significant. This effect can be observed on individual materials as well as on the average values (Figure 9).
The powder flow in experiments with a closed outlet show the highest volume flow rates for DCPA and MCC200, which is followed by SDL and MCC102. Volume flow rates are in the range of 123-424 ml/s. From the values provided in Table 4 and Figure 9 it is estimated that volume flow rates are distinctly different between most tested materials.

The volume flow rate of materials in an open outlet condition is in the range of $5900-12100 \mathrm{ml} / \mathrm{s}$. The variability between experiment repetitions is quite low, except for one experiment with MCC200 (Figure 9). DCPA and SDL have highest volume flow rates, whereas the volume flow rates of both MCC102 and MCC200 are distinctly lower.

Table 4. Volume flow rates in closed outlet, open outlet condition, and the condition without the pipe as measured $700 \mathrm{~mm}$ below knife valve for all tested materials: dicalcium phosphate anhydrous (DCPA), microcrystalline cellulose MCC102 and MCC200, and spray-dried lactose (SDL). The median value is presented with minimum and maximum values listed in parentheses.

\begin{tabular}{lccc}
\hline $\begin{array}{l}\text { Volume flow } \\
\text { rate [ml/s] }\end{array}$ & $\begin{array}{c}\text { Closed } \\
\text { outlet }\end{array}$ & $\begin{array}{c}\text { Open } \\
\text { outlet }\end{array}$ & $\begin{array}{c}\text { Without } \\
\text { the pipe }\end{array}$ \\
\hline DCPA & 424 & 12131 & 8199 \\
& $(414-523)$ & $(12060-12145)$ & $(8063-8336)$ \\
MCC102 & 123 & 6637 & 6568 \\
& $(122-134)$ & $(6394-6651)$ & $(6282-6854)$ \\
MCC200 & 386 & 5891 & 5256 \\
& $(360-431)$ & $(5654-8359)$ & $(3783 *-5256)$ \\
SDL & 241 & 10031 & 6408 \\
& $(227-265)$ & $(10028-10506)$ & $(5913-6903)$ \\
\hline
\end{tabular}

*Value excluded.

The condition without the pipe resulted in volume flow rates in the range of $5300-8200 \mathrm{ml} / \mathrm{s}$ and is distinctly lower for DCPA and SDL compared to volume flow rates measured in open outlet experiment (Figure 9). Volume flow rates for both MCC types are also lower, however the differences in volume flow rates between both outlet modes are smaller, even insignificant. 


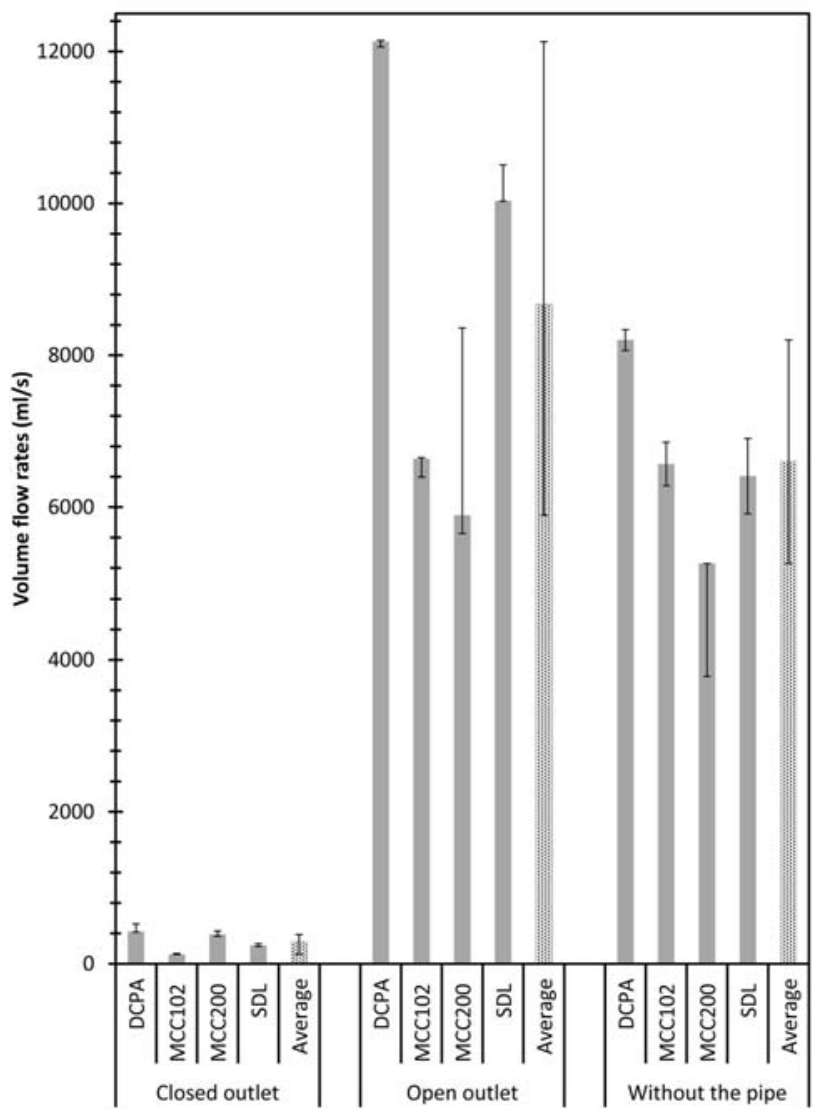

Figure 9. Volume flow rates in closed outlet, open outlet condition, and the condition without the pipe as measured $700 \mathrm{~mm}$ below knife valve for all tested materials: dicalcium phosphate anhydrous (DCPA), microcrystalline cellulose MCC102 and MCC200, and spray-dried lactose (SDL). Bar plots present median value, error bars indicate minimum and maximum values. For each condition average value of all tested materials is presented (blue) with error bars indicating minimum and maximum values.

Repeatability of flow experiments is suitable, considering stochastic nature of granular matter flow. However there were some instances, where anomalous results were obtained. There is one repetition of MCC200 in open outlet condition, where unexpectedly high volume flow rate was determined and one repetition of MCC200 in experiment without the pipe where volume flow rate was lower than expected (Figure 9). Both of these cases show that despite careful experimentation additional effects may influence the powder volume flow rates. Observed anomalous effects may be due to uneven material size distribution in bulk container or due to minute differences in powder packing in powder container.

Container discharge volume flow rates were measured for open outlet condition and condition without the pipe (Table 5): volume flow range from 3900-4900 ml/s for open outlet condition and $3700-4500 \mathrm{ml} / \mathrm{s}$ for condition without the pipe. Observed flows are about 1.3 to 2.5 ti- mes lower compared to flow measured in vertical pipe after $700 \mathrm{~mm}$ drop. This result was anticipated, since powder plug accelerates (Table 3) and after $700 \mathrm{~mm}$ drop much higher flow values are measured. Again a slight trend of faster flow for open outlet condition was observed and ranking of materials is similar as observed in volume flow experiments after $700 \mathrm{~mm}$ drop.

Table 5. Container discharge volume flow rates in open outlet condition, and the condition without the pipe for all tested materials: dicalcium phosphate anhydrous (DCPA), microcrystalline cellulose MCC102 and MCC200, and spray-dried lactose (SDL). The median value is presented with minimum and maximum values listed in parentheses.

\begin{tabular}{lcc}
\hline $\begin{array}{l}\text { Container discharge } \\
\text { volume flow rate } \\
(\mathbf{m l} / \mathbf{s})\end{array}$ & $\begin{array}{c}\text { Open } \\
\text { outlet }\end{array}$ & $\begin{array}{c}\text { Without } \\
\text { the pipe }\end{array}$ \\
\hline DCPA & 4852 & 4472 \\
& $(4824-4858)$ & $(4398-4547)$ \\
MCC102 & 3880 & 3712 \\
& $(3871-4263)$ & $(3712-3712)$ \\
MCC200 & 4284 & 4051 \\
SDL & $(4112-5016)$ & $(2671 *-4051)$ \\
& 4728 & 3985 \\
& $(4559-5014)$ & $(3942-4027)$ \\
\hline
\end{tabular}

*Value excluded.

Comparison of powder flow measurements from literature and our study is given in Table $6 .{ }^{3,4,18}$ The reference literature is however dealing with the steady state powder flow; all of the studies include mass flow hoppers with open outlet, only one of them ${ }^{3}$ includes also vertical pipe with open outlet. In addition, authors dealing with flow in narrow pipes do not provide the data which could enable direct comparison of the flow data. ${ }^{9,11}$

Although the experimental systems found in the literature are not completely comparable to our case, an attempt was made to compare literature powder flow data with our results. To enable the comparison the mass flow rates were calculated from volume flow rates, where necessary, and normalized to surface area of the powder outlet - i.e. mass flux of the granular flow was calculated (Table 6). Mass fluxes of granular flow in pipe with closed outlet are much lower compared to all of already published experiments, which is due to specific flow regime, which depends only on detachment events. The pipe with closed outlet has not been investigated in any of the references presented in Table 6 therefore no direct comparison with our results is appropriate. For the pipe with an open outlet used in this study, however, mass flux for DCPA is in the range of values for Sand $60^{3}$ and Sand, ${ }^{4}$ whereas mass flux for the MCC102 is similar to value for powdered coal. ${ }^{18}$ This comparison indicates that similar mass fluxes occur in systems (i.e. pipes or mass flow hoppers) with open outlets. 
Table 6. Comparison of flow data from literature for various materials (sand, sugar, PVC powder, powdered coal) with powder mass flow rates obtained in present study for dicalcium phosphate anhydrous (DCPA) and microcrystalline cellulose MCC102. Short description of test material and test system is provided, flow rates are normalized to outlet area and reported as mass flux of granular flow.

\begin{tabular}{|c|c|c|c|c|c|}
\hline Reference & $\begin{array}{c}\text { Material name } \\
\text { Mean particle size } \\
\text { Bulk density }\end{array}$ & System description & $\begin{array}{l}\text { Orifice } \\
\text { diameter } \\
(\mathrm{mm})\end{array}$ & $\begin{array}{c}\text { Mass } \\
\text { flow rate } \\
(\mathrm{kg} / \mathrm{s})\end{array}$ & $\begin{array}{c}\text { Calculated mass flux } \\
\text { of granular flow } \\
\left(\mathrm{g} / \mathrm{cm}^{2} \mathrm{~s}\right)\end{array}$ \\
\hline Pullen $^{3}$ & $\begin{array}{c}\text { Sand 60 } \\
461 \mu \mathrm{m} \\
1.588 \mathrm{~g} / \mathrm{ml} \\
\text { Sand 13/40 } \\
806 \mu \mathrm{m} \\
1.517 \mathrm{~g} / \mathrm{ml}\end{array}$ & $\begin{array}{c}\text { Double bin apparatus } \\
\text { with } 1500 \text { mm standpipe } \\
\text { with open outlet } \\
\text { attached; steady } \\
\text { statemass flow } \\
\text { measured. }\end{array}$ & 50.8 & 1.925 & 165.2 \\
\hline$\overline{\mathrm{Gu}^{4}}$ & $\begin{array}{c}\text { Sand } \\
201.6 \mu \mathrm{m} \\
1.329 \mathrm{~g} / \mathrm{ml} \\
\text { Sugar } \\
784 \mu \mathrm{m} \\
0.817 \mathrm{~g} / \mathrm{ml} \\
\text { PVC powder } \\
127 \mu \mathrm{m} \\
0.593 \mathrm{~g} / \mathrm{ml}\end{array}$ & $\begin{array}{l}\text { Double bin apparatus } \\
\text { with constant } \\
\text { fill height; } \\
\text { steady state mass } \\
\text { flow measured. }\end{array}$ & 44.5 & 0.878 & 48.2 \\
\hline Lu et al. ${ }^{18}$ & $\begin{array}{c}\text { Powdered coal } \\
224 \mu \mathrm{m} \\
0.727 \mathrm{~g} / \mathrm{ml}\end{array}$ & $\begin{array}{l}\text { Mass flow hopper; } \\
\text { steady state mass } \\
\text { flow measured. }\end{array}$ & 32 & 0.285 & 35.4 \\
\hline Present work & $\begin{array}{c}\text { DCPA } \\
132 \mu \mathrm{m} \\
0.688 \mathrm{~g} / \mathrm{ml} \\
\mathbf{M C C 1 0 2} \\
104 \mu \mathrm{m} \\
0.347 \mathrm{~g} / \mathrm{ml}\end{array}$ & $\begin{array}{l}\text { Vertical pipe } \\
\text { with closed outlet; } \\
\text { steady state mass } \\
\text { flow measured. }\end{array}$ & 70 & 0.292 & 7.6 \\
\hline & $\begin{array}{c}\text { DCPA } \\
132 \mu \mathrm{m} \\
0.688 \mathrm{~g} / \mathrm{ml} \\
\text { MCC102 } \\
104 \mu \mathrm{m} \\
0.347 \mathrm{~g} / \mathrm{ml}\end{array}$ & $\begin{array}{l}\text { Vertical pipe } \\
\text { with open outlet - } \\
\text { container discharge; } \\
\text { transient system. }\end{array}$ & 70 & 3.338 & 86.7 \\
\hline
\end{tabular}

\section{2. 3. 1. Correlation of Pipe Volume Flow Rates to Bulk Powder Properties}

Table 7 presents the association between bulk powder properties and volume flow rates for all outlet conditions. Pairs with significant linear correlation are graphically presented in Figure 10 with their respective linear correlation equations. In closed outlet condition the correlation is significant for funnel volume flow. This correlation indicates that the funnel flow tester used for routine powders evaluation in pharmaceutical industry (so called powder flowability) also takes into account processes which take place during powder flow in much broader pipes. More importantly, this correlation reveals that funnel flow testing can predict flow rates in pipes with closed outlet (Figure 10). This particular outlet condition resembles the tablet die filling phenomena, although on bigger scale and with higher length to diameter ratio. Pipe volume flow in open outlet condition is strongly correlated with bulk and tapped densities (Table 7, Figure 10); si- milar is indicated for condition without the pipe, however the correlation is not significant. Correlation of volume flow for the three outlet conditions was also performed with true density values, particle size values and angle of

Table 7. Correlation matrix between volume flow rate for all outlet conditions and bulk powder properties (bulk and tapped densities, funnel volume flow). Pairs where more than $50 \%$ of values were explained by powder property (coefficient of determination $\left(\mathrm{R}^{2}\right)>$ 0.5 ) are in bold. Pearson coefficient values with $P<0.05$ are labelled with an asterisk.

\begin{tabular}{lccc}
\hline & \multicolumn{3}{c}{ Pipe volume flow } \\
& $\begin{array}{c}\text { Closed } \\
\text { outlet }\end{array}$ & $\begin{array}{c}\text { Open } \\
\text { outlet }\end{array}$ & $\begin{array}{c}\text { Without } \\
\text { the pipe }\end{array}$ \\
\hline Bulk density & 0.423 & $\mathbf{0 . 9 8 7 *}$ & $\mathbf{0 . 7 5 8}$ \\
Tapped density & 0.360 & $\mathbf{0 . 9 9 7 *}$ & $\mathbf{0 . 8 1 9}$ \\
Funnel volume flow & $\mathbf{0 . 9 5 3 *}$ & 0.096 & -0.023 \\
\hline
\end{tabular}

$* \mathrm{P}<0.05$ 


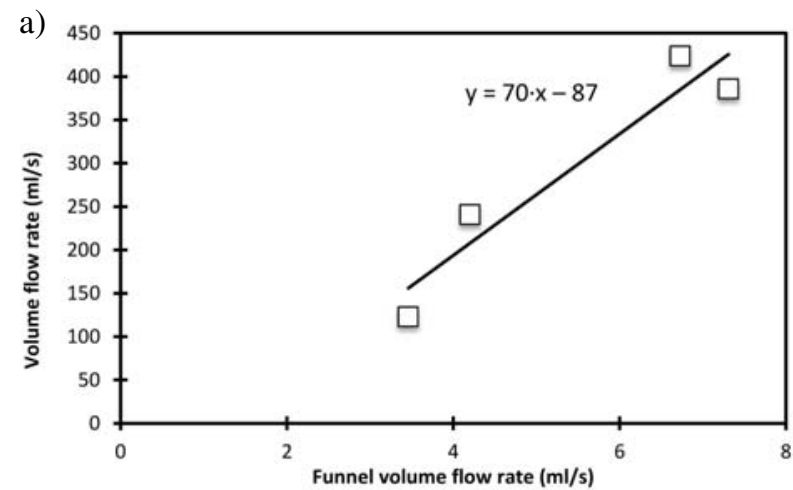

b)

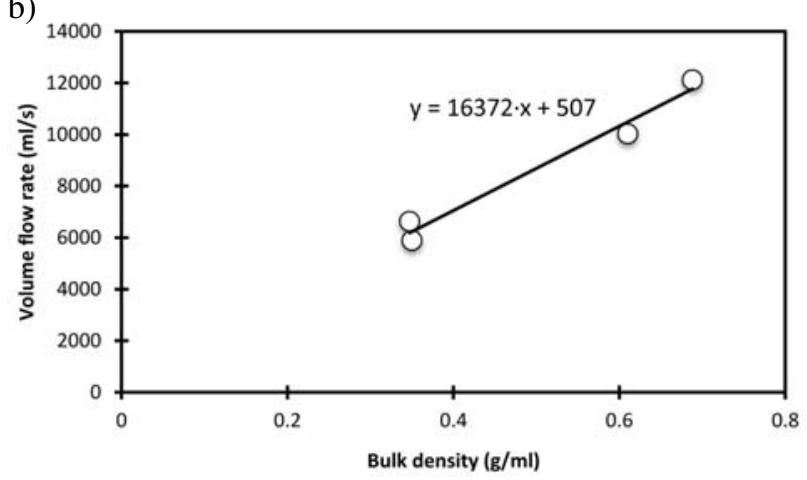

c)

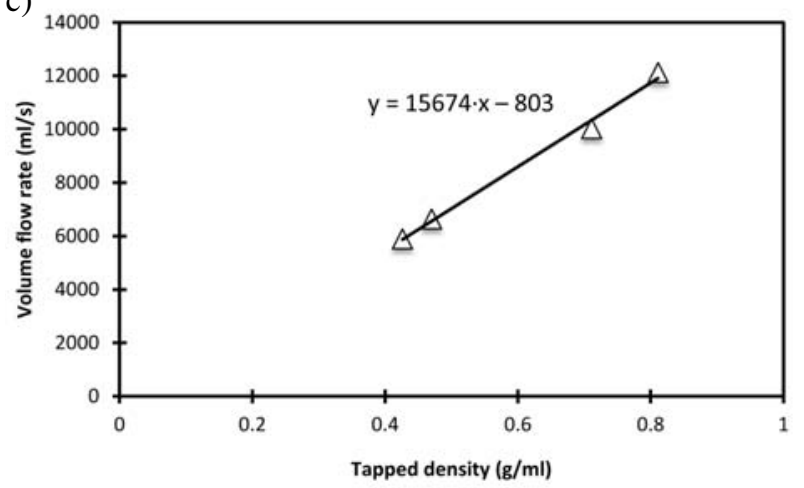

Figure 10: Linear correlations between powder volume flow rates (Table 4) and bulk powder properties (Table 7): closed outlet volume flow rate vs. funnel volume flow rate (top), open outlet pipe volume flow rate vs. bulk and tapped densities (middle and bottom). Only bulk powder properties with significant influence on volume powder flow are presented; linear correlation equations are reported.

repose, however no significant correlation was established (results not shown).

\section{Conclusions}

Detailed analysis of powder flow initiation, identification of predominant flow regimes and analysis of flow characteristics of individual powders through spatial-temporal images of powder flow in vertical pipes have been performed on industrially applicable pipe scale. A trans- parent vertical pipe setup enabled a detailed observation and study of gravity-driven powder flows, providing an opportunity for detailed qualitative descriptions, as well as quantitative measurements.

The pipe with the closed outlet exhibits two flow regimes: the first regime is a plug flow, which is a slow process depending on material permeability and the air volume rate of escaping air; the second regime is a dilute granular flow which occurs after the detachment of powder packets from the bottom part of the moving powder plug and their dispersion during the fall. The detachment frequency and the size of the detached parts are rate-limiting factors, which will influence powder flow rate in pipes with the closed outlet. In the case of stagnant flow - i.e. when detachment events are sporadically stopped, the powder flow will continue in the form of a slow plug flow.

In the closed outlet condition it was observed that falling powders in the dilute state transform into structures resembling Rayleigh-Taylor instability - a similarity with cases with a high Atwood number was observed. In the release condition without the pipe, the Rayleigh instability was identified in terms of plug surface undulations, manifesting on the dense powder flow upon the powder release into the air.

Powder front acceleration values for tested cases clearly demonstrate the degree of interaction between air and falling powder. Acceleration of the powder front is the lowest in the case of the closed pipe outlet, where air backflow is present, medium in the case of release into the standing air (case without the pipe), and the highest in the case of the open outlet, where the concurrent flow of air and powder were detected.

It was shown that powder volume flow rate in vertical pipes depends strongly on the pipe outlet condition. In pipes with the open outlet, powder flow is in the form of a dense granular flow and is an order of magnitude faster, compared to the pipe with an air-tightly closed outlet. Furthermore, in case of DCPA and SDL it was demonstrated that volume flow rates in the pipe with the open outlet are higher compared to the condition without the pipe. Volume flow rate for the closed outlet condition was correlated with the funnel volume flow; volume flow rate for the open outlet condition was correlated with bulk and tapped powder densities.

Powder flow in vertical pipes is a process rarely studied in detail despite its widespread presence: experiments - as presented in this study - are crucial for improved understanding of powder flow and provide an experimental basis for mathematical model improvement as well as an opportunity for verification of simulation approaches.

\section{Acknowledgements}

Authors would like to thank Lek d.d. for financial support, which enabled building of the testing apparatus. 


\section{References}

1. R. D. Marcus, L. S. Leung, G. E. Klinzing, F. Rizk, Pneumatic Conveying of Solids, Springer Netherlands, Dordrecht, Netherlands, 1990, pp. 309-337.

http://dx.doi.org/10.1007/978-94-009-0405-7_8

2. A. W. Jenike, Bull. Univ. Utah. 1961, 52, 1-309.

3. R. J. F. Pullen, Studies of solids flowing downwards from a hopper trough a vertical pipes, $\mathrm{PhD}$ Thesis, The University of Leeds, Leeds, UK, 1974.

4. Z. H. Gu, Gravity flowrate of bulk solids from mass flow bins, PhD Thesis, University of Wollongong, Wollongong, Australia, 1991.

5. T. Deng, K. A. Paul, M. S. A. Bradley, L. Immins, C. Preston, J. F. Scott, E. H. Welfare, Powder Technol. 2010, 203, 354-358. http://dx.doi.org/10.1016/j.powtec.2010.05.028

6. J. K. Prescott, in: M. Levin (Ed.): Pharmaceutical process scale-up, CRC Press, Boca Raton, USA, 2011, pp. 195-209.

7. Z. Chowan, Pharm. Technol. 1995, 19(5), 56-70.

8. M. Jaklič, K. Kočevar, S. Srčič, R. Dreu, Powder Technol. 2015, 278, 171-180. http://dx.doi.org/10.1016/j.powtec.2015.03.021

9. Y. Bertho, F. Giorgiutti-Dauphiné, J. P. Hulin, Phys. Fluids. 2003, 15, 3358-3369. http://dx.doi.org/10.1063/1.1615570

10. T. Raafat, J. P. Hulin, H. J. Herrmann, Phys Rev E. 1996, 53, 4345-4350. http://dx.doi.org/10.1103/PhysRevE.53.4345

11. S. Horikawa, T. Isoda, T. Nakayama, A. Nakahara, M. Matsushita, Phys. Stat. Mech. Its Appl. 1996, 233, 699-708. http://dx.doi.org/10.1016/S0378-4371(96)00156-2

12. E. D. Liss, S. L. Conway, B. J. Glasser, Phys. Fluids. 2002, 14, 3309-3326. http://dx.doi.org/10.1063/1.1499126

13. M. Ostendorf, J. Schwedes, in: A. Levy, C. J. Kalman (Ed.): Handbook of Conveying and Handling of Particulate Solids, Elsevier, Amsterdam, Netherlands, 2001, pp. 851-860.

http://dx.doi.org/10.1016/S0167-3785(01)80087-7
14. M. Horio, R. P. Kobylecki, M. Tsukada, in: W-C. Yang (Ed.): Handbook of fluidization and fluid-particle systems, Marcel Dekker, New York, USA, 2003, pp. 644-705.

15. Y. M. Chen, S. Rangachari, R. Jackson, Ind. Eng. Chem. Fundam. 1984, 23, 354-370. http://dx.doi.org/10.1021/i100015a016

16. J. L. Sinclair, R. Jackson, AIChE J. 1989, 35, 1473-1486. http://dx.doi.org/10.1002/aic.690350908

17. J. C. Ginestra, S. Rangachari, R. Jackson, Powder Technol. 1980, 27, 69-84. http://dx.doi.org/10.1016/0032-5910(80)85043-1

18. H. Lu, X. Guo, Y. Liu, X. Gong, KONA Powder Part. J. 2015, 32, 143-153. http://dx.doi.org/10.14356/kona.2015002

19. L. S. Fan, C. Zhu, Principles of gas-solid flows, Cambridge University Press, Cambridge, UK, 2005, pp. 346-359.

20. Flowability, in: European Pharmacopoeia, 8th Edition, Council of Europe, Strasbourg, France, 2015, p. 307.

21. R. C. Rowe, P. J. Sheskey, M. E. Quinn (Ed.): Handbook of pharmaceutical excipients, Pharmaceutical Press, London, UK, 2009, pp. 94, 131, 365.

22. G. Dimonte, D. L. Youngs, A. Dimits, S. Weber, M. Marinak, S. Wunsch, C. Garasi, A. Robinson, M. J. Andrews, P. Ramaprabhu, A. C. Calder, B. Fryxell, J. Biello, L. Dursi, P. MacNeice, K. Olson, P. Ricker, R. Rosner, F. Timmes, H. Tufo, Y-N. Young, and M. Zingale, Phys. Fluids. 2004, 16, 1668-1693. http://dx.doi.org/10.1063/1.1688328

23. G. C. Burton, Cent. Turbul. Res. Annu. Res. Briefs. 2009 , 273-284.

24. D. Livescu, M. R. Petersen, S. L. Martin, P. S. McCormick, Spikes and Bubbles in Turbulent Mixing: High Atwood Number Rayleigh-Taylor Instability, http://www.aps.org /units/dfd/pressroom/gallery/2009/livescu.cfm, (assessed: June 7, 2015)

\section{Povzetek}

Gravitacijski transport granularnih snovi po vertikalnih cevnih povezavah je osnoven in hkrati ključen proces, ki se odvija pri procesiranju granularnih snovi. Proučevali smo tokovne strukture farmacevtskih praškov pri različnih pogojih izpusta vertikalne cevne povezave: zaprta cev, odprta cev in izpust brez cevi. Granularni tok smo opazovali na steklenem, prosojnem, laboratorijskem modelu vertikalne cevne povezave. Opisali smo tokovne strukture padajočih praškov, s slikovno analizo pa smo kvantificirali tokovne parametre (volumski pretok, pospeški, dilatacija) in jih korelirali z izmerjenimi lastnostmi praškov. Volumski pretok praškov v cevi z zaprtim dnom je za red velikosti manjši v primerjavi s pretokom $\mathrm{v}$ cevi $\mathrm{z}$ odprtim dnom. V cevi z zaprtim dnom se granularni tok pod vplivom izhajajočega zraka organizira $\mathrm{v}$ dva tokovna režima: počasen tok gostega nasutja praškov in hiter, redek tok praškov, dispergiranih v izhajajočem zraku. V cevi z odprtim dnom smo opazili hiter, gosti tok granularne snovi. Razlike med opisanimi tokovnimi režimi dveh pogojev izpusta so lahko osnova za segregacijo granularne snovi, kar lahko kritično vpliva na industrijske tehnološke procese. 